\title{
Susceptibility of three orthopteran species to infection by Metarhizium acridum (Hypocreales: Clavicipitaceae)
}

\author{
Francisco Guilherme Vergolino Schmidt ${ }^{1}$, \\ Pâmela de Jesus Conceição ${ }^{2}$, Norton Polo Benito ${ }^{1}$ \\ and Rogerio Biaggioni Lopes ${ }^{1 *}$ \\ ${ }^{1}$ EMBRAPA Genetic Resources and Biotechnology, 70849-970 Brasília, DF, Brazil; \\ ${ }^{2}$ Federal University of Bahia Recôncavo, 44380-000 Cruz das Almas, BA, Brazil
}

(Accepted 13 June 2017)

\begin{abstract}
Outbreaks of three orthopteran species-Tropidacris collaris (Stoll), Cornops frenatum frenatum (Marschall) and Parascopas obesus (Giglio-Tos)-occurred in three different regions of Brazil during the summers of 2012 and 2013. Insects were observed causing severe damage in commercial crops and subsistence farming areas. In this study, the three species were shown to be susceptible to infection with an oil-based formulation of the fungus Metarhizium acridum under laboratory conditions. In this article, we briefly discuss insect mortality levels for each species and behavioural response to infection. This is the first report of the pathogenicity of the entomopathogenic fungus $M$. acridum to P. obesus, C. f. frenatum and T. collaris.
\end{abstract}

Key words: Metarhizium acridum, Tropidacris collaris, Cornops $f$. frenatum, Parascopas obesus, biological control

\section{Introduction}

Several species of locusts and grasshoppers have caused huge losses to crops in Brazil in the past years. Seasonal outbreaks of species in the genera Rhammatocerus and Schistocerca (Orthoptera: Acrididae), usually influenced by favourable environmental conditions, were observed during the 1980s and 1990s invading large areas (Barrientos, 1995). More recently, increasing populations of other orthopteran species have been reported in native savanna and crop areas in the central regions of the country (Guerra et al., 2010). In this study, we describe the occurrence of Tropidacris collaris (Stoll) (Romaleidae: Romaleinae), Cornops frenatum frenatum (Marschall) (Acrididae: Leptysminae) and Parascopas obesus (Giglio-Tos) (Acrididae: Melanoplinae) in three different Brazilian biomes. We identified

*E-mail: rogerio.lopes@embrapa.br large populations of these three orthopteran species in 2012 and 2013 causing severe damage in commercial crops and subsistence farming areas. Identification of non-chemical alternatives for control of these pests is considered important, due to the proximity of the infested areas to ecological preservation biomes and family settlements. The use of microbial products based on the fungus Metarhizium against orthopteran pests has been reported in Africa, Australia, China and also in Brazil, in response to environmental concerns over the heavy use of chemical insecticides (Magalhães et al., 2000; Hunter et al., 2001; Lomer et al., 2001; Faria et al., 2002; Long and Hunter, 2005; Peng et al., 2008). The goal of the present study was to evaluate the biocontrol potential of an indigenous strain of Metarhizium acridum (Driver \& Milner) Bischoff, Rehner \& Humber (Hypocreales: Clavicipitaceae) against these species, by host susceptibility bioassays under laboratory conditions. 


\section{Materials and Methods}

Specimens of T. collaris, C. f. frenatum and $P$. obesus were collected feeding on rubber tree, banana and maize, respectively, using an entomological net or by hand in 2012 and 2013. Groups of between 30 and 50 individuals were kept for 30 days in cages and fed on their respective host plants until used in experiments. During the quarantine period, dead and weak insects were removed periodically, and natural infection by other microorganisms and parasitism by parasitoids was evaluated.

The indigenous strain of $M$. acridum CG423, originally isolated from Schistocerca pallens, was used in the susceptibility bioassays. It has been tested in field trials and shown to be effective against Rhammatocerus schistocercoides (Rehn) (Orthoptera: Acrididae) (Magalhães et al., 2001). The fungus was grown on potato dextrose agar medium (PDA, Difco $^{\circledR}$ ) for 10 days at $25 \pm 0.5^{\circ} \mathrm{C}$ and $12 \mathrm{~h}$ photophase. Fresh conidia were suspended in soybean oil at a concentration of $1 \times 10^{8}$ conidia/ml. Conidial viability in stock suspension was determined as $>92 \%$ at the time of the bioassays. Conidia were applied topically with a glass microsyringe using doses between $1 \times 10^{4}$ and $1 \times 10^{5}$ conidia/insect. Insect inoculation, experimental units (two groups of 15-20 insects) and materials were similar among the tested species, with slight variations. Cornops $f$. frenatum adults were inoculated on the abdominal sternal region ( $1 \mu \mathrm{l}$ drop with $2 \times 10^{4}$ conidia/insect) and fed on banana and heliconia leaves. For P. obsesus inoculation and drop volume were the same as those used for C. f. frenatum; however, fourth instar nymphs were used, and two doses $\left(1\right.$ and $2 \times 10^{4}$ conidia/insect) were tested, because of the abundance of the nymphal stage in the collected samples. Parascopas obsesus nymphs were fed on grass leaves. For T. collaris adults were treated on the left thoracic sternal region, between the second and third legs, and fed on cashew tree leaves. A higher dose $(5 \mu 1$ drop with $1 \times 10^{5}$ conidia/insect) was used in this case, because of the low efficacy of the fungus in preliminary tests using lower doses. For each test, a control group of insects was treated with a drop of soybean oil ( 1 or $5 \mu \mathrm{l})$ without conidia on the same body region. Insects were kept in cages at room temperature $\left(25 \pm 2{ }^{\circ} \mathrm{C}\right)$ and checked every 2 or 3 days. Dead insects were removed and placed into a moistened chamber for confirmation of infection by the fungus. Survival analysis was used to estimate the time to $50 \%$ insect mortality $\left(\mathrm{ST}_{50}\right)$ and Log-rank testing with $5 \%$ probability was applied for comparisons between survival curves ( $R$ Statistical Software).

\section{Results and Discussion}

Adults and nymphs of the orthopteran species were observed in the Brazilian biomes of Caatinga,
Cerrado (savanna) and Pantanal (west border of Paraguay River), infesting and causing damage to crops and/or undisturbed native areas. The regions where the insects were collected are shown in Fig. 1. Insect infestations occurred in 2012 and 2013 during the summer period, which is characterized by high temperatures $\left(28-35^{\circ} \mathrm{C}\right)$ and high humidity $(>60 \%)$.

Tropidacris collaris adults and nymphs were found feeding on young rubber plants in a 200 ha plantation in the state of Tocantins, near an important environmentally protected unit $\left(11^{\circ} 20^{\prime} 34^{\prime \prime} \mathrm{S} / 46^{\circ} 45^{\prime} 38^{\prime \prime} \mathrm{W}\right)$. The area is part of the ecological corridor that connects important conservation units of the region of Jalapão. The large size and voracious feeding behaviour of the species caused a complete defoliation of young trees in some plots. At night and early mornings, because of the lower temperatures, adults were observed grouped on native tree branches near to the commercial crop. This is a typical behaviour of some orthopteran species seeking the sunlight to increase their activity.

Cultivated areas of heliconia flowers in a region known as "Portal do Sertão" (12 211'14"S / $38^{\circ} 48^{\prime} 16^{\prime \prime} \mathrm{W}$ ) have suffered economically important losses from C. f. frenatum since 2012. The region, located between the biomes of Caatinga and Mata Atlântica in the Northeast of Bahia state, covers almost $116,000 \mathrm{~km}^{2}$ and is an important new area of ornamental plant production. The species is also a voracious defoliator of heliconia and first became a serious problem of this tropical flower in cultivated areas of the Brazilian Amazon (Braga et al., 2007; Lemos et al., 2010; Ribeiro et al., 2013). Infestation of new regions, as observed in Bahia, was probably due to the introduction of plants from infested areas, favoured by the endophytic oviposition behaviour of the females.

A large number of nymphs of Parascopas spp. were observed infesting an area of almost 10 ha of a family settlement of a Brazilian governmental programme, nearby the Pantanal biome $\left(19^{\circ} 05^{\prime} 37^{\prime \prime} \mathrm{S} / 57^{\circ} 41^{\prime} 59^{\prime \prime} \mathrm{W}\right)$. Subsistence crops, mainly maize and pasture, of around 3 ha each spread over a larger native area, were harmed by seasonal insect infestations in 2012 and 2013, decreasing grain production and limiting cattle and dairy expansion. The main species occurring in the area was identified as P. obesus, although the species $P$. dubius was also collected in lower numbers.

Natural parasitism by insects or microorganisms was undetected in any of the collected samples of the three species maintained in quarantine in the laboratory. Metarhizium acridum was found to be pathogenic to all tested Acridoidea species, with insect survival decreasing with time after inoculation (Fig. 2). Significant differences in survival curves between fungus-treated and untreated insects were 


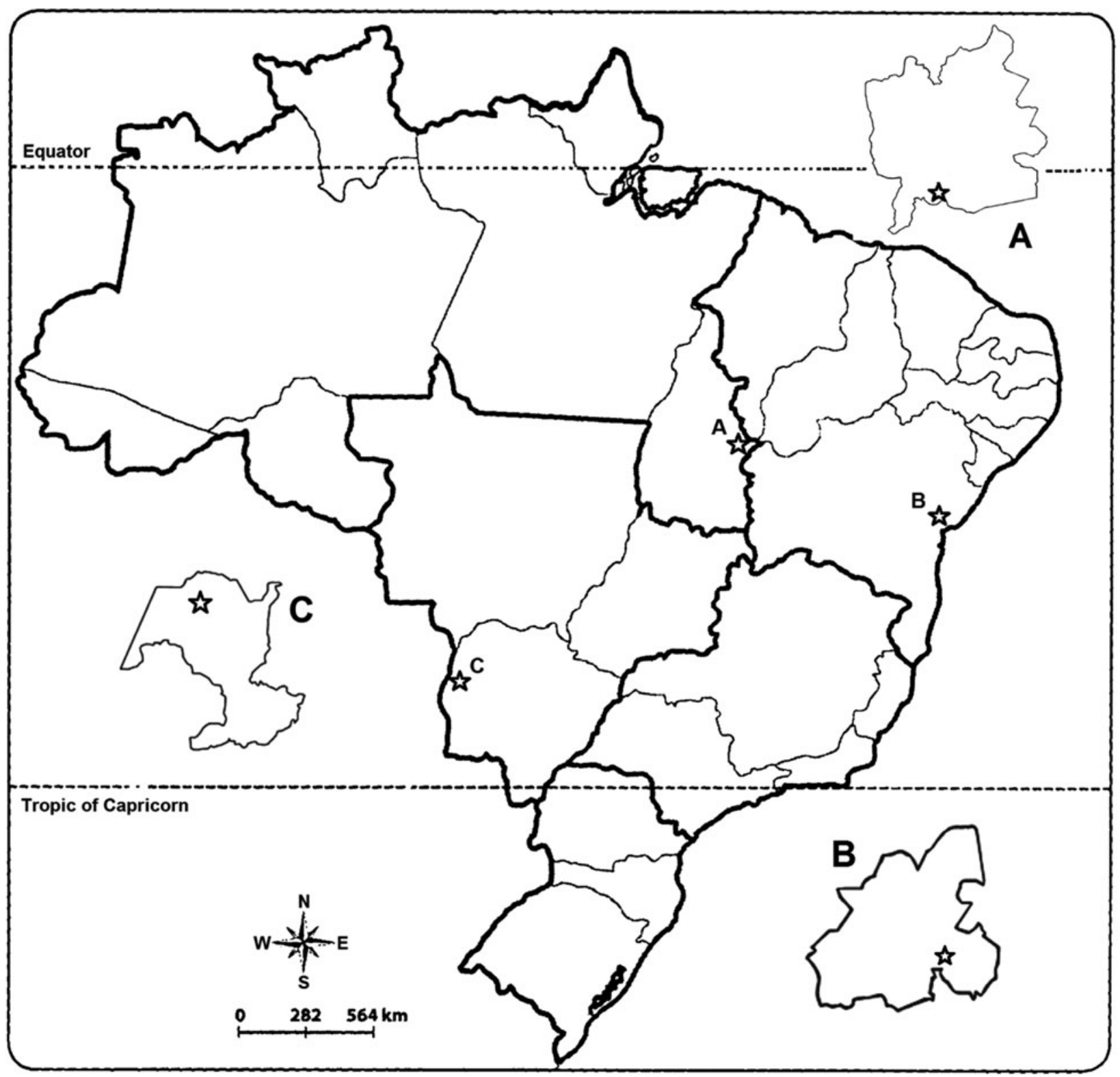

Fig. 1. Map of Brazil showing locations of Tropidacris collaris, Cornops frenatum frenatum and Parascopas obesus occurrence during 2012 and 2013 in the regions near Jalapão reserve in the state of Tocantins (A); heliconia crop areas in the state of Bahia (B); and farms of subsistence crops in the state of Mato Grosso do Sul (C)

observed for T. collares $\left(\chi^{2}=66.2, \mathrm{df}=1, P<0.0001\right)$, C. f. frenatum $\left(\chi^{2}=43.6, \mathrm{df}=1, P<0.0001\right)$ and $P$. obesus in both doses $\left(\chi^{2}=37.7, \mathrm{df}=1, P<\right.$ 0.0001 and $\left.\chi^{2}=26.7, \mathrm{df}=1, P<0.0001\right)$. Although mortality reached more than $90 \%$ at the end of the experimental period, the speed of insect kill varied among species. The larger species (T. collaris) took longer to reach $50 \%$ mortality $\left(\mathrm{ST}_{50}=15.7\right.$ days (15.3-16.1 days)), than the smaller C. $f$. frenatum $\left(\mathrm{ST}_{50}=11.1\right.$ days (10.8-11.4 days)) (Fig. 2A and D). Soybean oil showed some lethal effects, especially on nymphs of P. obesus, interfering with the normal moulting process. Although insect mortality in the control treatments (oil without conidia) was high, the increase of the dose led to a decrease of the survival time for $P$. obesus nymphs $\left(\mathrm{ST}_{50}=10.2\right.$ days (9.9-10.5 days) and $\mathrm{ST}_{50}=4.8$ days (4.7-4.9 days) for 1 and $2 \times 10^{4}$ conidia/insect, respectively) (Fig. 2B and C). Dead insects showed the typical symptoms of M. acridum infection, represented first by pink-red coloured integument followed by greenolive conidiation on inter-segmental regions of the body, mainly on the legs and thorax. Interestingly, abundant conidiation was unseen on T. collaris 
A

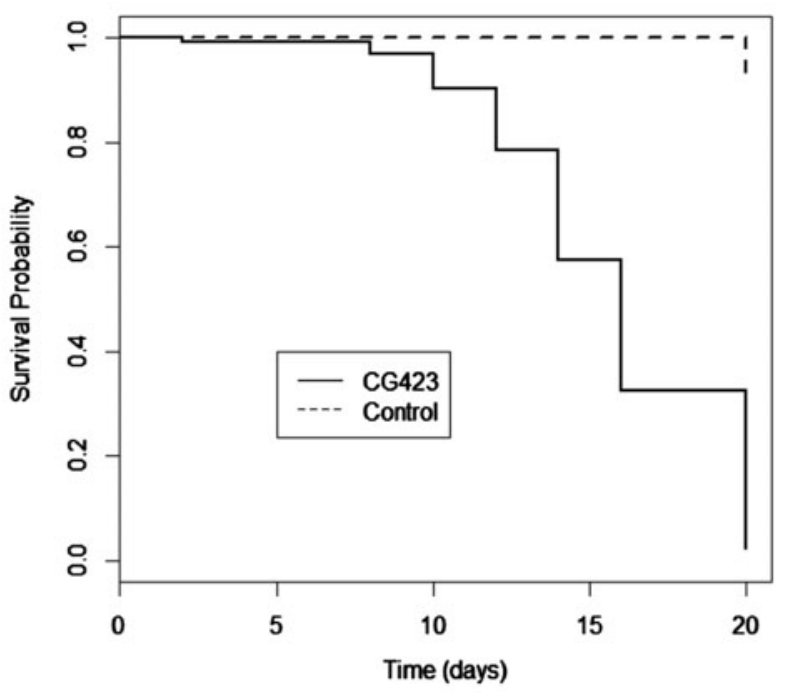

C

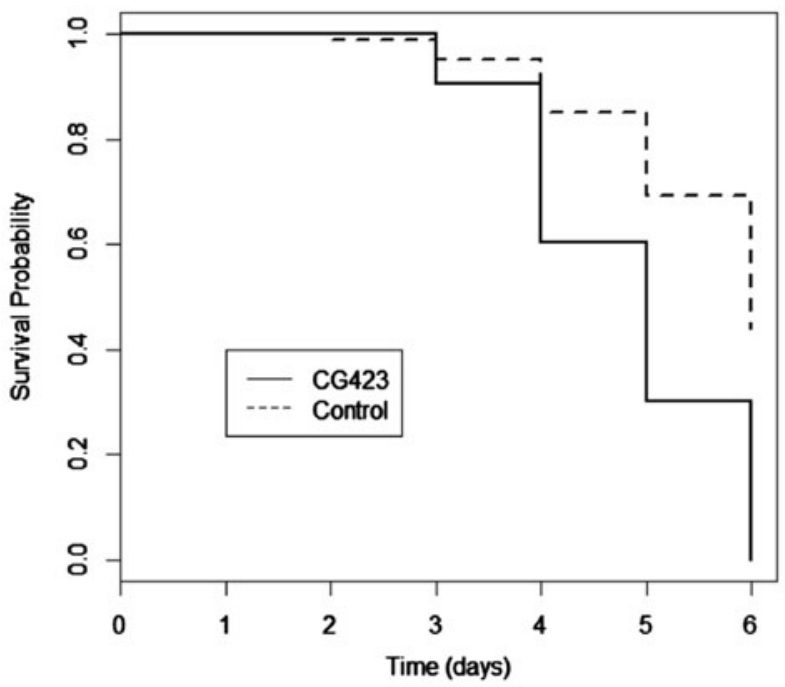

B

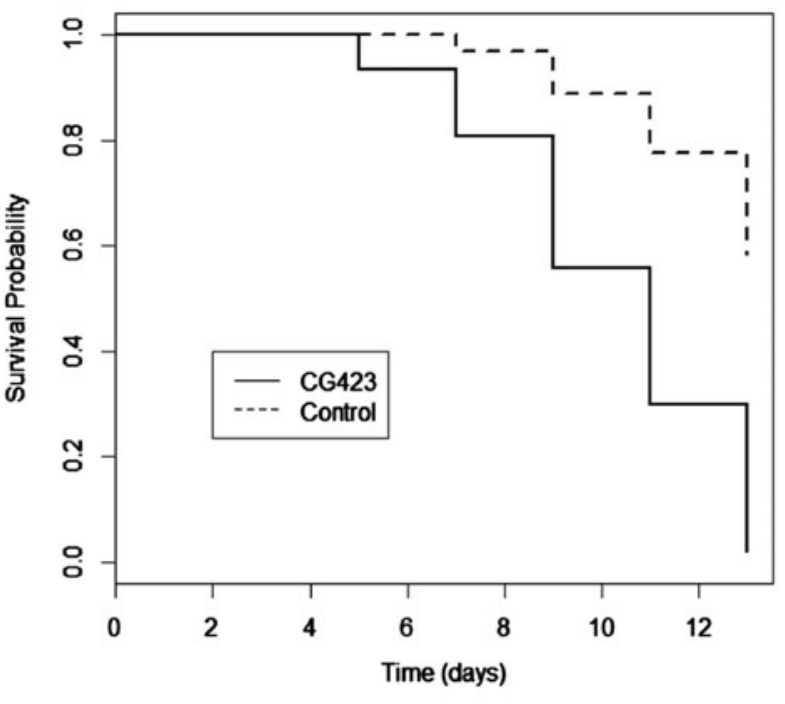

D

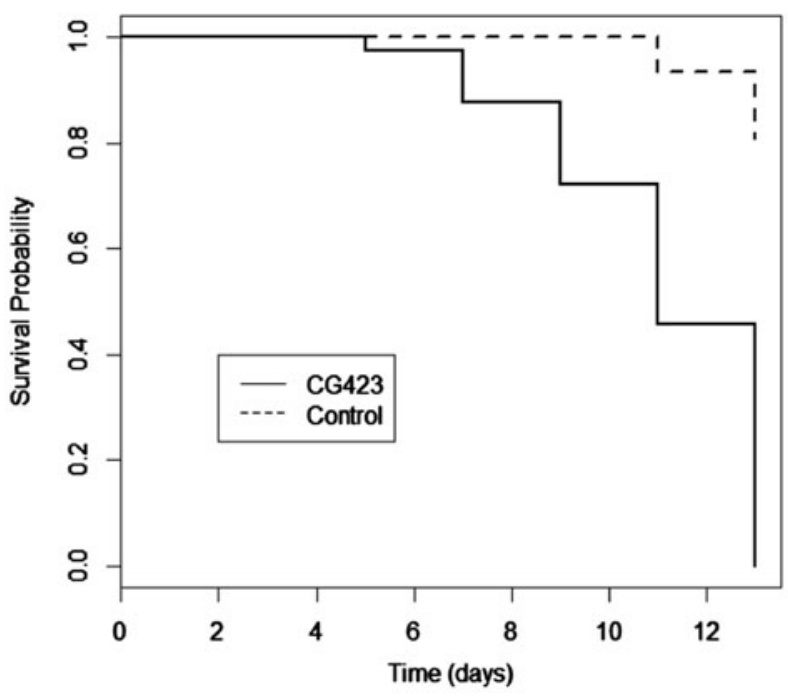

Fig. 2. Survival probability of insects treated with an oil-based formulation of Metarhizium acridum (CG423) under laboratory conditions. Tropidacris collaris: $1 \times 10^{5}$ conidia per adult (A); Parascopas obesus: $1 \times 10^{4}$ conidia per nymph (B); $2 \times 10^{4}$ conidia per nymph (C); and Cornops frenatum frenatum: $2 \times 10^{4}$ conidia per adult (D).

cadavers. Probably, the thick and rigid tegument of this species hindered fungal reproduction on the cadaver surface. However, a huge number of conidial clusters were observed inside thoracic cavities of mummified cadavers after dissection.

Studies have reported the susceptibility of acridids to Metarhizium under laboratory conditions (Magalhães et al., 2001; Hernández-Velázquez et al., 2003; Tounou et al., 2008). Estimated mean survival time varied from a few days to almost a week, depending on the insect species and developmental stage, concentration and inoculation method, exper- imental conditions, fungal strain and formulation. Although our results confirmed the susceptibility of all three orthopteran species to $M$. acridum, differences on the susceptibility level among these species are difficult to determine, due to methodological variation. Despite the voracity of these species and the absence of the 'knock down' effect of the fungus, we observed that insects are affected by infection and their feeding and mobility behaviour differed from healthy insects, as also reported in previous studies (Faria et al., 1999; Magalhães et al., 2001). The consumption of plant leaves by 
the infected groups before death was less than observed in the control groups. The susceptibility of the three orthopteran species to $M$. acridum reported here provides important information for the future development of an environmentally safe control alternative against these pests in Brazil.

\section{References}

Barrientos L. L. (1995) The present state of the locust and grasshopper problem in Brazil. Journal of Orthoptera Research 4, 61-64.

Braga C. E., Nunes A. L. and Adis J. (2007) Cornops frenatum frenatum (Marschall, 1836) (Orthoptera: Acrididae, Leptysminae): ocorrência e oviposição em quatro espécies de Heliconia (Heliconiaceae) na Amazônia Central, Brasil. Amazoniana 3, 227-231.

Dias-Guerra W., Oliveira P. C. and Barrientos-Lozano L. (2010) Life history and population dynamics of Baeacris punctulatus (Thunberg, 1824) (Orthoptera: Acrididae) in the state of Mato Grosso, Brazil. Journal of Orthoptera Research 19, 333-340.

Faria M. R., Almeida D. O. and Magalhães B. P. (1999) Food consumption of Rhammatocerus schistocercoides Rehn (Orthoptera: Acrididae) infected by the fungus Metarhizium flavoviride Gams \& Rozsypal. Anais da Sociedade Entomológica do Brasil 28, 91-99.

Faria M. R., Magalhães B. P., Alves R. T., Schmidt F. G. V., Silva J. B. T. and Frazão H. (2002) Effect of two dosages of Metarhizium anisopliae var. acridum against Rhammatocerus schistocercoides Rehn. Pesquisa Agropecuária Brasileira 37, 1531-1539.

Hernández-Velázquez V. M., Hunter D. M., BarrientosLozano L., Lezama-Gutiérrez R. and Reyes-Villanueva F. (2003) Susceptibility of Schistocerca piceifrons (Orthoptera: Acrididae) to Metarhizium anisopliae var. acridum (Deuteromycotina: Hyphomycetes): laboratory and field trials. Journal of Orthoptera Research 12, 89-92.

Hunter D. M., Milner R. J. and Spurgin P. A. (2001) Aerial treatment of the Australian plague locust, Chortoicetes terminifera (Orthoptera: Acrididae) with Metarhizium anisopliae (Deuteromycotina: Hyphomycetes). Bulletin of Entomological Research 91, 93-99.

Lemos W. P., Ribeiro R. C., Lhano M. G., Silva J. P. S. and Zanuncio J. C. (2010) Cornops frenatum frenatum (Marschall) (Orthoptera: Acrididae, Leptysminae) in crops of tropical flowers of Heliconia spp. in the State of Pará, Brazil. Entomotropica 25, 43-47.

Lomer C. L., Bateman R. P., Johnson D. L., Langewald J. and Thomas M. (2001) Biological control of locusts and grasshoppers. Annual Review of Entomology 46, 667702.

Long Z. and Hunter D. M. (2005) Laboratory and field trials of Green Guard ${ }^{\circledR}$ (Metarhizium anisopliae var. acridum) (Deuteromycotina: Hyphomycetes) against the oriental migratory locust (Locusta migratoria manilensis) (Orthoptera: Acrididae) in China. Journal of Orthoptera Research 14, 27-30.

Magalhães B. P., Faria M. R., Lecoq M., Schmidt F. G. V., Silva J. B. T., Frazão H. S., Balança G. and Foucart A. (2001) The use of Metarhizium anisopliae var. acridum against the grasshopper Rhammatocerus schistocercoides in Brazil. Journal of Orthoptera Research 10, 199-202.

Magalhães B. P., Lecoq M., Faria M. R., Schmidt F. G. V. and Guerra W. D. (2000) Field trial with the entomopathogenic fungus Metarhizium anisopliae var. acridum against bands of the grasshopper Rhammatocerus schistocercoides in Brazil. Biocontrol Science and Technology 10, 427-441.

Peng G., Wang Z., Yin Y., Zeng D. and Xia Y. (2008) Field trials of Metarhizium anisopliae var. acridum (Ascomycota: Hypocreales) against oriental migratory locusts, Locusta migratoria manilensis (Meyen) in Northern China. Crop Protection 27, 1244-1250.

Ribeiro R. C., Lemos W. P., Poderoso J. C. M., Pikart T. G. and Zanuncio J. C. (2013) New record of grasshopper (Orthoptera: Acrididae \& Romaleidae) defoliators and population dynamics of insects on crops of Heliconia spp. in the Amazon. Florida Entomologist 96, 225-228.

Tounou A. K., Kooyman C., Douro-Kpindou O.K. and Poehling H.M. (2008) Interaction between Paranosema locustae and Metarhizium anisopliae var. acridum, two pathogens of the desert locust, Schistocerca gregaria under laboratory conditions. Journal of Invertebrate Pathology 97, 203-210. 